suppression held 24 hours after shock, the maximum recovery time (means+S.D.) of subsidiary pacemaker in group A,B and C was $9160+2166,4713+$ $1423,930+712 \mathrm{msec}$ and the corrected maximum recovery time (means+S.D.) of subsidiary pacemaker in group A, B and C was $6657+2024,3326+980$, $906+574 \mathrm{msec}$ respectively. The total recovery time (means + S.D.) in group $A, B$ and $C$ was $92+5$, $57+26,32+9 \mathrm{sec}$.

2) In Holter ECG recorded after the shock, mean heart rate of the stable state in group $A, B$ and $C$ was $34+8,47+4,56+10 \mathrm{bpm}$, and the maximum pause in group $\mathrm{A}, \mathrm{B}$ and $\mathrm{C}$ was $7.5+1.2,5.7+0.9$, $1.7+0.2 \mathrm{sec}$.

3) The histological findings of myocardial damage were minimum in group $\mathrm{C}$ and more extensive in group A.

Thus, the degree of myocardial damage by the electrical shock was one of the contributing factors of the suppression in subsidiary pacemaker function after electrical ablation of atrioventricular junction.

\section{$-190-$ \\ EFFECTIVENESS OF A TRANSARTERIAL CATHETER TECHNIQUE FOR ELECTRICAL ABLATION OF ATRIOVENTRICULAR JUNCTION IN DOGS}

Kazuo Moroe, Tadayuki Hiroki, Yasushi Sasaki, Keisuke Fukuda, Kikuo Arakawa

The Second Department of Internal Medicine Fukuoka University School of Medicine

To analyze the effectiveness of a transarterial catheter technique for electrical ablation of atrioventricular junction(AVJ), twenty-six mongrel dogs were studied by means of synchronized direct current electrical shock between the catheter adjacent to the non-coronary cusp and metal plate behind the dog's back. We classified these dogs into 3 groups according to the energy, namely high energy of more than $200 \mathrm{~J}$ (group A), the medium energy (group B), and low energy of 20 or $40 \mathrm{~J}$ (group $\mathrm{C}$ ).

Resu1t; 1) Complete A-V block was induced by a single shock in all dogs. 2) Ventricular premature beat (VPB) appeared after the shock in a11 dogs in group A, 2 of four dogs in group B, however no VPB was seen in group $C$. Ventricular fibrillation was induced in 1 of twelve in group A. Ventricular tachycardia appeared after the shock in 6 of twelve in group A, 2 of four in group B, and none in group C. 3) Although in 9 of twelve in group $A$, transient pacing were performed, no pacing was needed in group $C$. 4) The QRS duration of escaped rhythm after the shock in group $\mathrm{A}, \mathrm{B}$ and $\mathrm{C}$ was $99+17,85+5,58+8 \mathrm{msec}$. That is the QRS duration of escaped rhythm in the high energy group was significantly longer than the low energy group. 5) The histological findings of myocardial damage were correlated with the amount of energy delivered.

This transarterial technique of low energy may be applicable for clinical use.

$-191-$

ELECTROPHYSIOLOGIC EFFECTS OF NICAINOPROL ON THE RABBIT ATRIOVENTRICULAR NODE
Takeshi Noda, Yoshizumi Habuchi, Akihiko Miyakawa, Masao Nishimura, Yoshio Watanabe

Cardiovascular Institute, Fujita Gakuen University, Toyoake, Aichi, Japan

Electrophysiologic effects of a new antiarrhythmic agent nicainoprol $\left(10^{-6}, 10^{-5}, 10^{-4} \mathrm{~g} / \mathrm{ml}\right)$ were studied in small preparations $(0.2 \times 0.2 \times 0.1 \mathrm{~mm})$ of the rabbit atrioventricular (AV) node. In spontaneously beating preparations, this agent at $10^{-6} \mathrm{~g} / \mathrm{ml}$ caused a slight reduction in the firing frequency. At $10^{-5} \mathrm{~g} / \mathrm{ml}$, it decreased the maximal rate of depolarization from 19.2 to $13.1 \mathrm{~V} / \mathrm{sec}$ without affecting the take-off potential. Action potential duration at 100 repolarization was prolonged from 132 to $143 \mathrm{msec}$ and the spontaneous rate was reduced 184 to $154 / \mathrm{min}(\mathrm{p}<0.05, \mathrm{n}=6)$. These changes were exaggerated at $10^{-4} \mathrm{~g} / \mathrm{ml}$. Essentially the same results were obtained in the rate-controlled or tetrodotoxintreated AV nodal cells. Voltage clamp experiments using double microelectrode method revealed that nicainoprol decreased the slow inward current ( $i_{s}$ ) from -36.6 to $-29.7 \mathrm{nA}(\mathrm{p}<0.05, \mathrm{n}=5)$ without shifting its inactivation kinetics, although the inactivation time constant was minimally increased from 13.2 to $15.3 \mathrm{msec}$. This agent reduced the outward $\mathrm{K}^{+}$current $\left(i_{k}\right)$ tail from 12.7 to $9.3 \mathrm{nA}(p<0.05, n=6)$, but did not affect its activation kinetics and deactivation time constant. Nicainoprol decreased the hyperpolarization activated inward current $\left(i_{h}\right)$ by about $10 \%$. These results suggest that 1) nicainoprol exerts its antiarrhythmic actions possibly by suppressing AV nodal conduction and prolonging the refractory period and 2) these effects are attributed to a reduction all the ionic currents including $i_{s}, i_{k}$ and $i_{h}$.

\section{Chairmen}

192-200 T. Kozuka, Osaka Y. Inagaki, Chiba

\section{$-192-$ \\ ECHOCARDIOGRAPHIC FINDINGS AND X-RAY CT FINDINGS OF PERICARDIAL EFFUSION AND SUBEPICARDIAL FAT}

Akihiko Kagaya, Hiroshi Aoyagi,

Nobuhiro Morooka, Sigeru Watanabe,

Masaki Syukuya, Yoshiaki Masuda,

Yoshiaki Inagaki

The 3rd. Department of Internal Medicine,

Chiba University of School of Medicine

It is difficult to distinguish pericardial effusion from subepicardial fat with ultrasound, but X-ray CT easily differentiate effusion from fat. So we attempt to compare the feature of pericardial effusion and subepicardial fat with both methods in 75 subjicts who had echo free space surrounding the heart. Subepicardial fat was frequently found above the right and left ventricle, but was not found above the right and left atrium. While, pericardial effusion was found most frequently in front of the right ventricle, occasionally at the lateral side of atrium and the posterior side of left ventricle, but rarely found behind the left atrium. The amount of subepicardial fat increased significantly with age, Broca index, total serum cholesterol, and the deposition of the subcutaneous body fat. In many subjects the echo- 